\title{
Notas Científicas \\ Cinetina e nitrato de potássio em características agronômicas de soja
}

\author{
Alexandre Martins Abdão dos Passos ${ }^{(1)}$, Pedro Milanez de Rezende ${ }^{(1)}$, Eudes de Arruda Carvalho(1) \\ e Roberto Antonio Martinez Savelli ${ }^{(1)}$
} (1)Universidade Federal de Lavras, Departamento de Agricultura, Caixa Postal 37, CEP 37200-000 Lavras, MG. E-mail: aabdao@terra.com.br,
pmrezend@ufla.br, eudes@agronomia.ufla.br, robertosavelli@hotmail.com

\begin{abstract}
Resumo - O objetivo deste trabalho foi avaliar o efeito do fitorregulador cinetina e do nitrato de potássio, aplicados via foliar na fase fenológica R3, sobre algumas características agronômicas da soja e sua produtividade em campo. Utilizaram-se cinco doses de cinetina, combinadas com quatro doses de nitrato de potássio, em esquema bi-fatorial, em delineamento de blocos ao acaso. A aplicação de nitrato de potássio não influenciou as características agronômicas avaliadas. A cinetina aumentou em até $27,4 \%$ o número de legumes fixados. O peso de 1.000 sementes e a produtividade de grãos foram aumentados em até 2,7 e $32,3 \%$, respectivamente.
\end{abstract}

Termos para indexação: Glycine max, citocinina, fitorregulador, nutrição mineral.

\section{Kinetin and potassium nitrate effects on agronomic characteristics of soybean}

\begin{abstract}
The aim of this work was to evaluate the effect of kinetin and of potassium nitrate, applied on leaves in the phenological phase R3, on some agronomic characteristics of soybean plants and their yield in field. Five concentrations of kinetin combined with four concentrations of potassium nitrate were used in an outline bi-factorial, in a randomized block experimental design, with three replications. The potassium nitrate application did not influence the studied agronomic characteristics. Kinetin increased the pod set number up to $27.4 \%$, in contrast to the control. Kinetin increased the weight of 1,000 seeds and the yield up to 2.7 and 32.3\%, respectively.
\end{abstract}

Index terms: Glycine max, cytokinin, plant growth substances, plant nutrition.

Por meio da adoção de elevado nível de tecnologia e manejo da cultura, o cultivo da soja no Brasil tem se destacado mundialmente. Entretanto, existem ainda alguns fatores que poderiam proporcionar à cultura patamares de produtividade acima dos estabelecidos até o momento.

Alguns estudos têm mostrado uma forte tendência tecnológica para o uso de citocininas sintéticas, aplicadas via foliar, associadas ou não a nutrientes, como formas de manejo para aumentar a produtividade da soja (Crosby et al., 1981; Carlson et al., 1987; Dyer et al., 1987; Mosjidis et al., 1993; Nagel et al., 2001; Cho et al., 2002; Liu et al., 2004; Yashima et al., 2005; Nonokawa et al., 2007). Nessa leguminosa, um elevado número de flores e de legumes jovens é abortado naturalmente, o que representa um impacto negativo na produtividade (Nonokawa et al., 2007).
Os principais fatores envolvidos na fixação de legumes de soja são a disponibilidade de nutrientes e de fotoassimilados destinados a esses legumes, quando em desenvolvimento (Wiebold, 1990), assim como a disponibilidade de algumas classes de hormônios nas sementes (Crosby et al., 1981; Carlson et al., 1987; Kokubun \& Honda, 2000; Yashima et al., 2005). Pesquisas indicam a existência de deficiência de citocinina endógena, no terço superior do racemo em plantas de soja, que se encontra correlacionada ao maior aborto das partes reprodutivas da planta (Kokubun \& Honda, 2000; Nonokawa et al., 2007).

Em estudos recentes com essa leguminosa, realizados no Japão, Nonokawa et al. (2007) constataram que as aplicações exógenas de BAP nos racemos, após a antese, aumentaram o número de legumes produzidos pela planta. 
Apesar dos resultados positivos, com relação ao uso isolado da citocinina exógena, no aumento de produtividade na cultura da soja, há carência de estudos quanto aos seus efeitos em condições brasileiras e inexistem trabalhos realizados a campo.

Cuquel et al. (2001) observam que, sob condições de deficiência nutricional, diminuem as concentrações endógenas de citocininas e que a aplicação de citocininas exógenas minimiza os sintomas de deficiência.

O fertilizante nitrato de potássio é tido como um adubo potássico, por apresentar em sua composição cerca de $44 \%$ de $\mathrm{K}_{2} \mathrm{O}$ e apenas $13 \%$ de N. Nelson et al. (2005) avaliaram, durante dois anos, diferentes doses e épocas de aplicação de K, por via foliar, à cultura da soja, e concluíram que esse tipo de aplicação não substitui o K aplicado ao solo; no entanto, ressaltam que a aplicação foliar pode ser uma opção de adubação suplementar, quando as condições edafoclimáticas não forem favoráveis à absorção do $\mathrm{K}$ oriundo do solo, o que proporciona significativo aumento de produtividade.

Neste trabalho, objetivou-se verificar os efeitos da cinetina associada ao nitrato de potássio, aplicados via foliar durante a fase reprodutiva (R3), sobre a produtividade e outras características agronômicas da soja.

O experimento foi conduzido no Município de Itutinga, MG, a $21^{\circ} 23^{\prime} \mathrm{S}, 44^{\circ} 39^{\prime} \mathrm{W}$, e altitude média de $958 \mathrm{~m}$, em solo do tipo Cambissol, com textura argilosa (530 $\mathrm{g} \mathrm{kg}^{-1}$ de argila), com dois anos de cultivo, considerado solo de média a alta fertilidade, constatado por sua análise química: pH em água, 5,5; $\mathrm{P}$ (Mehlich 1), 2,5 $\mathrm{mg} \mathrm{dm}^{-3}$; $\mathrm{K}$ (Mehlich 1), $145 \mathrm{mg} \mathrm{dm}^{-3} ; \mathrm{Ca}(\mathrm{KCl}), 2,6 \mathrm{mmol}_{\mathrm{c}} \mathrm{dm}^{-3}$; $\mathrm{Mg}(\mathrm{KCl}), 0,7 \mathrm{mmol}_{\mathrm{c}} \mathrm{dm}^{-3} ; \mathrm{H}+\mathrm{Al}$ (tampão SMP), 3,2 $\mathrm{mmol}_{\mathrm{c}} \mathrm{dm}^{-3} ; \mathrm{T}, 6,9 \mathrm{mmol}_{\mathrm{c}} \mathrm{dm}^{-3} ; \mathrm{MO}, 34 \mathrm{~g} \mathrm{~kg}^{-1}$; e $\mathrm{V}, 53,4 \%$.

A adubação de semeadura foi realizada de acordo com a análise de solo, tendo-se utilizado $400 \mathrm{~kg} \mathrm{ha}^{-1}$ do formulado 0-30-10. As sementes de soja foram submetidas à inoculação de Bradyrhizobium japonicum, na proporção mínima de $12 \times 10^{-5}$ células da bactéria por semente. $\mathrm{O}$ delineamento experimental utilizado foi o de blocos ao acaso, em esquema fatorial $5 \times 4$, com três repetições, que consistiram de cinco concentrações de cinetina $(0,250,500$, 750 e $\left.1.000 \mathrm{mg} \mathrm{ha}^{-1}\right)$ e quatro de nitrato de potássio $(0,5$, 10 e $15 \mathrm{~kg} \mathrm{ha}^{-1}$ ), com aplicação foliar na fase fenológica de início da formação dos legumes (R3), por meio de pulverizador com pressão de $\mathrm{CO}_{2}$, à pressão constante de $2,8 \mathrm{kgf} \mathrm{cm}^{-2}$, e com volume de calda de $200 \mathrm{~L} \mathrm{ha}^{-1}$. A dosagem zero correspondeu ao controle, com aplicação apenas de água.

Para a realização do experimento, foi utilizada a cultivar BRSGO Luziânia. As parcelas no campo foram constituídas de quatro fileiras de $5 \mathrm{~m}$, espaçadas entre si em $0,5 \mathrm{~m}$, e foram retiradas, como bordadura, duas fileiras externas e $0,5 \mathrm{~m}$ de cada extremidade das fileiras centrais.

$\mathrm{Na}$ fase de maturação (R8), com uma amostragem de dez plantas nas fileiras úteis, estimou-se o número dos legumes por planta, número de sementes por legume, peso de 1.000 sementes, altura da planta $(\mathrm{cm})$ e da inserção do primeiro legume $(\mathrm{cm})$. Posteriormente à amostragem, realizou-se a colheita das parcelas inteiras, em que se avaliou a produtividade (corrigida a umidade dos grãos para $13 \%$ ).

Os dados obtidos nas diferentes avaliações foram submetidos ao teste $\mathrm{F}$, para análise de variância e, os efeitos dos tratamentos, quando significativos, foram submetidos à análise de regressão.

Não houve efeito da interação, entre a cinetina e o nitrato de potássio, sobre as características agronômicas avaliadas da cultura da soja (Tabela 1). A cinetina proporcionou aumento no peso de 1.000 sementes (PMS), no número total de legumes por planta (LegT) e na produtividade (ProdT). Entretanto, o nitrato de potássio não apresentou efeito significativo nas características agronômicas avaliadas da cultura.

Tabela 1. Análise de variância dos dados relativos à altura de plantas (AltPlant), altura de inserção do primeiro legume (AltLeg), número de sementes por legume (SemLeg), peso de 1.000 sementes (PMS), número total de legumes por planta (LegT) e produtividade (ProdT), obtidos como efeito da aplicação de cinetina e nitrato de potássio na soja.

\begin{tabular}{|c|c|c|c|c|c|c|c|}
\hline \multirow[t]{2}{*}{ Causas de variação } & \multirow[t]{2}{*}{ GL } & \multicolumn{6}{|c|}{ Quadrados médios } \\
\hline & & AltPlant & AltLeg & SemLeg & PMS & LegT & ProdT \\
\hline$\overline{\text { Blocos }}$ & 2 & 776 & 8,3 & 0,02 & 45,1 & 111,0 & 509.144 \\
\hline Cinetina $(\mathrm{C})$ & 4 & 48 & 3,6 & 0,04 & $49,6^{*}$ & $245,9 * *$ & $1.857 .420 * *$ \\
\hline Nitrato $(\mathrm{N})$ & 3 & 112 & 0,1 & 0,004 & 9,9 & 28,8 & 22.308 \\
\hline $\mathrm{C} \times \mathrm{N}$ & 12 & 98 & 1,9 & 0,02 & 6,0 & 7,3 & 254.750 \\
\hline Resíduo & 38 & 142 & 2,2 & 0,02 & 15,6 & 16,9 & 189.890 \\
\hline Médias & & 85 & 16 & 2 & 163 & 59 & 3.765 \\
\hline $\mathrm{CV}(\%)$ & & 14,0 & 9,0 & 6,8 & 2,4 & 6,6 & 11,6 \\
\hline
\end{tabular}

* e **Significativo a 5 e $1 \%$ de probabilidade, respectivamente, pelo teste $\mathrm{F}$. 
Este resultado é condizente com ensaios realizados em solução nutritiva, em que a infusão de $\mathrm{K}$ via xilema, em plantas de soja, não aumentou significativamente o número de legumes, o peso dos grãos e a produtividade (Grabau et al., 1986). As condições do experimento podem ter colaborado para a ausência de efeito da adubação foliar potássica na lavoura, uma vez que a aplicação de K via foliar pode ser uma boa opção de adubação suplementar, apenas quando as condições edafoclimáticas não forem favoráveis à absorção regular do K oriundo do solo (Nelson et al., 2005).

A aplicação de cinetina proporcionou aumento significativo no PMS (Tabela 1). Resultados coincidentes foram observados por autores que utilizaram citocininas sintéticas (Carlson et al., 1987; Dyer, et al., 1987). Esses resultados podem ter ocorrido em razão do acúmulo de matéria seca, que se inicia nas partes vegetativas da planta; porém, entre R3 e R5, há translocação gradativa para os legumes e grãos em formação (Ritchie et al., 1997). Nessa situação, a aplicação de citocininas exógenas pode aumentar a força de dreno para esses grãos e incrementar o peso deles.

A utilização da cinetina via foliar proporcionou ganho significativo no número de legumes totais fixados nas plantas, com aumento médio de 6,9 legumes por planta $(12,1 \%)$, em relação ao tratamento testemunha (Figura 1).

A utilização da cinetina proporcionou ganho significativo de produtividade na cultura, com aumento médio de 22,5\% (718 $\mathrm{kg} \mathrm{ha}^{-1}$ ), em relação ao tratamento testemunha. A maior dosagem proporcionou ganhos de até $32,3 \%\left(1.030 \mathrm{~kg} \mathrm{ha}^{-1}\right)$.

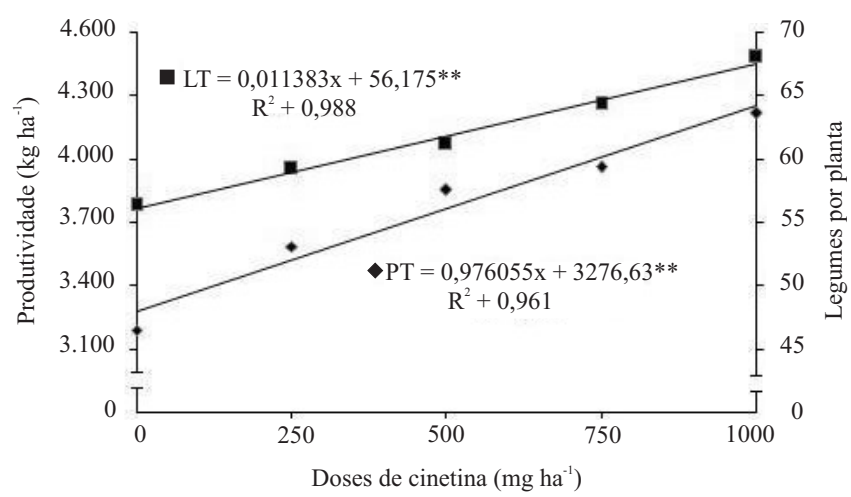

Figura 1. Produtividade (PT) e número de legumes por planta (LT), em razão das doses de cinetina aplicadas no estádio R3.
Esses aumentos são consistentes com dados da literatura, para a cultura da soja em condições de cultivo protegido e de campo (Crosby et al., 1981; Carlson et al., 1987; Dyer et al., 1987; Mosjidis et al., 1993; Nagel et al., 2001; Cho et al., 2002; Liu et al., 2004; Yashima et al., 2005; Nonokawa et al., 2007).

Um importante papel das citocininas é o de promover a expansão foliar e, conseqüentemente, a formação de fotoassimilados necessários ao enchimento de grãos. Regulam também, entre outros fatores, a síntese dos pigmentos e proteínas fotossintéticas. Esses fatos podem influenciar diretamente o balanço da fotossíntese, o que resulta em maior produção de fotoassimilados e indica, dessa forma, maior produtividade de grãos.

Além da maior produção de fotoassimilados, pela maior taxa fotossintética mediante o aumento da área foliar e dos teores de clorofila, é importante a utilização dessas reservas nos órgãos de interesse econômico, que no caso da soja, são os grãos. Nesse sentido, a capacidade das citocininas em regular a relação de forças entre as fontes e drenos pode exercer importante papel para o aumento de produtividade da lavoura, por meio da fixação de legumes e aumento do acúmulo de matéria seca dos grãos, durante a fase R3 (Liu et al., 2004; Yashima et al., 2005; Nonokawa et al., 2007).

A aplicação da cinetina via foliar, durante o início da frutificação da soja, representa tecnologia promissora de produção para a cultura, pois proporciona aumento significativo na produtividade, número de legumes por planta e peso de 1.000 sementes.

A aplicação do nitrato de potássio via foliar, na fase R3, não é prática fitotécnica recomendada, pois não afeta nenhuma das características avaliadas.

\section{Referências}

CARLSON, D.R.; DYER, D.J.; COTTERMAN, C.D.; DURLEY, R.C. The physiological basis for cytokinin induced increases in pod set in IX93-100 soybeans. Plant Physiology, v.84, p.233-239, 1987.

CHO, Y.; SUH, S.K.; PARK, H.K.; WOOD, A. Impact of 2,4-DP and BAP upon pod set and seed yield in soybean treated at reproductive stages. Plant Growth Regulation, v.36, p.215-221, 2002.

CROSBY, K.E.; AUNG, L.H.; BUSS, G.R. Influence of 6-benzylaminopurine on fruit-set and seed development in two soybean Glycine max (L.) Merr. genotypes. Plant Physiology, v.68, p.985-988, 1981.

CUQUEL, F.L.; CLARK, D.G.; MINAMI, K. Horticultural performance of transgenic Petunia x hybrid plants containing the 
PSAG12-ipt gene grown under nutritional deficiency. Revista Brasileira de Horticultura Ornamental, v.7, p.41-48, 2002. DYER, D.J.; CARLSON, D.R.; COTTERMAN, C.D.; SIKORSKI, J.A.; DITSON, S.L. Soybean pod set enhancement with synthetic cytokinin analogs. Plant Physiology, v.84, p.240-243, 1987.

GRABAU, L.J.; BLEVINS, D.G.; MINOR, H.C. P nutrition during seed development: leaf senescence, pod retention, and seed weight of soybean. Plant Physiology, v.82, p.1008-1012, 1986.

KOKUBUN, M.; HONDA, I. Intra-raceme variation in pod-set probability is associated with cytokinin content in soybeans. Plant Production Science, v.3, p.354-359, 2000.

LIU, F.; JENSEN, C.R.; ANDERSEN, M.N. Drought stress effect on carbohydrate concentration in soybean leaves and pods during early reproductive development: its implication in altering pod set. Field Crops Research, v.86, p.1-13, 2004.

MOSJIDIS, C.O.; PETERSON, C.M.; TRUELOVE, B.; DUTE, R.R. Stimulation of pod and ovule growth of soybean, Glycine max (L.) Merr. by 6-benzylaminopurine. Annals of Botany, v.71, p.193199, 1993.
NAGEL, L.; BREWSTER, R.; RIEDELL, W.E.; REESE, R.N. Cytokinin regulation of flower and pod set in soybeans (Glycine $\max ($ L.) Merr.). Annals of Botany, v.88, p.27-31, 2001.

NELSON, K.A.; MOTAVALLI, P.P.; NATHAN, M. Response of no-till soybean [Glycine $\max (\mathrm{L}$.) Merr.] to timing of preplant and foliar potassium applications in a claypan soil. Agronomy Journal, v.97, p.832-838, 2005.

NONOKAWA, K.; KOKUBUN, M.; NAKAJIMA, T.; NAKAMURA, T.; YOSHIDA, R. Roles of auxin and cytokinin in soybean pod setting. Plant Production Science, v.10, p.199-206, 2007.

RITCHIE, S.W.; HANWAY, J.J.; THOMPSON, H.E.; BENSON, G.O. How a soybean plant develops. Ames: Iowa State University of Science and Technology Cooperative Extension Service, 1997. 20p. (Special Report, n.53).

WIEBOLD, W.J. Rescue of soybean flowers destined to abscise. Agronomy Journal, v.82, p.85-88, 1990.

YASHIMA, Y.; KAIHATSU, A.; NAKAJIMA, T.; KOKUBUN, M. Effects of source/sink ratio and cytokinin application on pod set in soybean. Plant Production Science, v.8, p.139-144, 2005.

Recebido em 20 de outubro de 2007 e aprovado em 16 de junho de 2008 